\title{
LOS APROVECHAMIENTOS FORESTALES EN LAS SIERRAS DEL CORREDOR Y EL MONTNEGRE A MEDIADOS DEL SIGLO XIX
}

\author{
Luis Urteaga \\ Francesc Nadal \\ Departament de Geografia Humana. Universitat de Barcelona \\ urteaga@ub.edu,fnadal@ub.edu
}

\section{RESUMEN}

Este trabajo utiliza la información contenida en los amillaramientos para realizar una aproximación a la distribución del espacio forestal en las sierras del Corredor y el Montnegre a mediados del siglo XIX. La misma fuente fiscal, suplementada con la consulta de las cartillas evaluatorias y los expedientes de reclamación de agravio, se emplea para efectuar una descripción de los aprovechamientos del monte. El examen complementario de la Estadística General del Comercio de Cabotaje permite una aproximación al tráfico de productos forestales en la zona, y aporta evidencias adicionales acerca de las especies objeto de transacción comercial. Por último, se estudian algunas de las principales actividades transformadoras vinculadas a los recursos forestales.

Palabras clave: geografía histórica, geografía rural, recursos forestales, sierras del Montnegre y el Corredor.

\section{ABSTRACT}

Forest harvesting in the mountains of the Corredor and Montnegre mid-nineteenth century. This paper uses the information contained in the territorial tax statistics («amillaramientos») to make an approximation to the distribution of forest areas in the mountains of the Corredor and Montnegre mid-nineteenth century. The same source, supplemented by other

Fecha de recepción: septiembre 2011.

Fecha de aceptación: enero 2013. 
information provided by fiscal claim files, is used to make a description of the uses of the forest. The scrutiny of the General Statistics of the coasting trade («Estadística General del Comercio de Cabotaje») allows an approach to trafficking in forest products in the area, and provides additional evidence about the species traded. Finally, it discusses some of the main processing activities related to forest resources.

Key words: historical geography, rural geography, forest resources, mountains of Montnegre and Corredor.

\section{INTRODUCCIÓN}

Los bosques de los macizos del Corredor y el Montnegre, objeto de un intenso aprovechamiento desde la edad media, fueron sometidos a una fuerte presión durante el ochocientos. Entre las causas de esta intensificación de los aprovechamientos del monte figuran la creciente demanda de madera para la construcción naval, el consumo de combustible en los hornos de vidrio y en otras actividades industriales, y la extensión de la red ferroviaria por el norte de la comarca del Maresme, que revalorizó los recursos forestales de la zona al facilitar su extracción.

Estudios recientes han identificado las profundas transformaciones del paisaje ocurridas en la zona del Montnegre-Corredor durante el siglo XIX (Casals et. al., 2005; Serra y Pintó, 2005; Parcerisas y Tello, 2011). Sin embargo, buena parte del esfuerzo erudito se ha centrado en la evolución paisajística a largo plazo, dejando en un plano secundario la caracterización de los aprovechamientos y la especificación de su importancia económica. Nuestro trabajo pone el énfasis en las utilidades del bosque, y lo hace en un período crucial en la evolución de los montes: los años centrales del ochocientos ${ }^{1}$.

La fuente principal de este trabajo son los amillaramientos correspondientes a 1852 y 1862, así como la documentación fiscal conexa a los mismos: cartillas evaluatorias, expedientes de reclamación de agravio por exceso de cuota, y expedientes de comprobación. Diversos especialistas en historia rural han justificado el valor heurístico de los amillaramientos compilados en Cataluña a mediados del siglo XIX (Segura, 1990; Colomé, 1996 y 1997; Valls, 1996; Vallejo, 2001). Nuestras propias investigaciones sobre la cartografía catastral ochocentista permiten añadir algún argumento adicional sobre esta cuestión (Nadal, Urteaga y Muro, 2005 y 2006; Montaner, Nadal y Urteaga, 2011).

La formación y aprobación de los amillaramientos de 1852 estuvo acompañada, en el área de estudio, por una completa indagación estadística, que desembocó en el levantamiento de los planos parcelarios de la mayor parte de los municipios de la zona. A partir de 1851, y casi siempre por iniciativa y a cargo de los propios ayuntamientos, se efectuó el levantamiento cartográfico de los términos municipales de Calella (1851), Dosrius (1851-53), Fogars de Tordera (1853), Mataró (1851), Palafolls (1853), Sant Andreu de Llavaneres (1851); Sant

1 Este trabajo se ha realizado en el marco del proyecto de investigación CSO2008-06031-C02-01/GEOG, financiado por la Dirección General de Investigación del Ministerio de Ciencia y Tecnología. Queremos agradecer la generosa ayuda de la Diputació de Barcelona durante la fase de trabajo de archivo. Agradecemos los comentarios de Vicenç Casals a una primera versión del texto, y la ayuda de Alexandre Nobajas en la preparación de los mapas. 


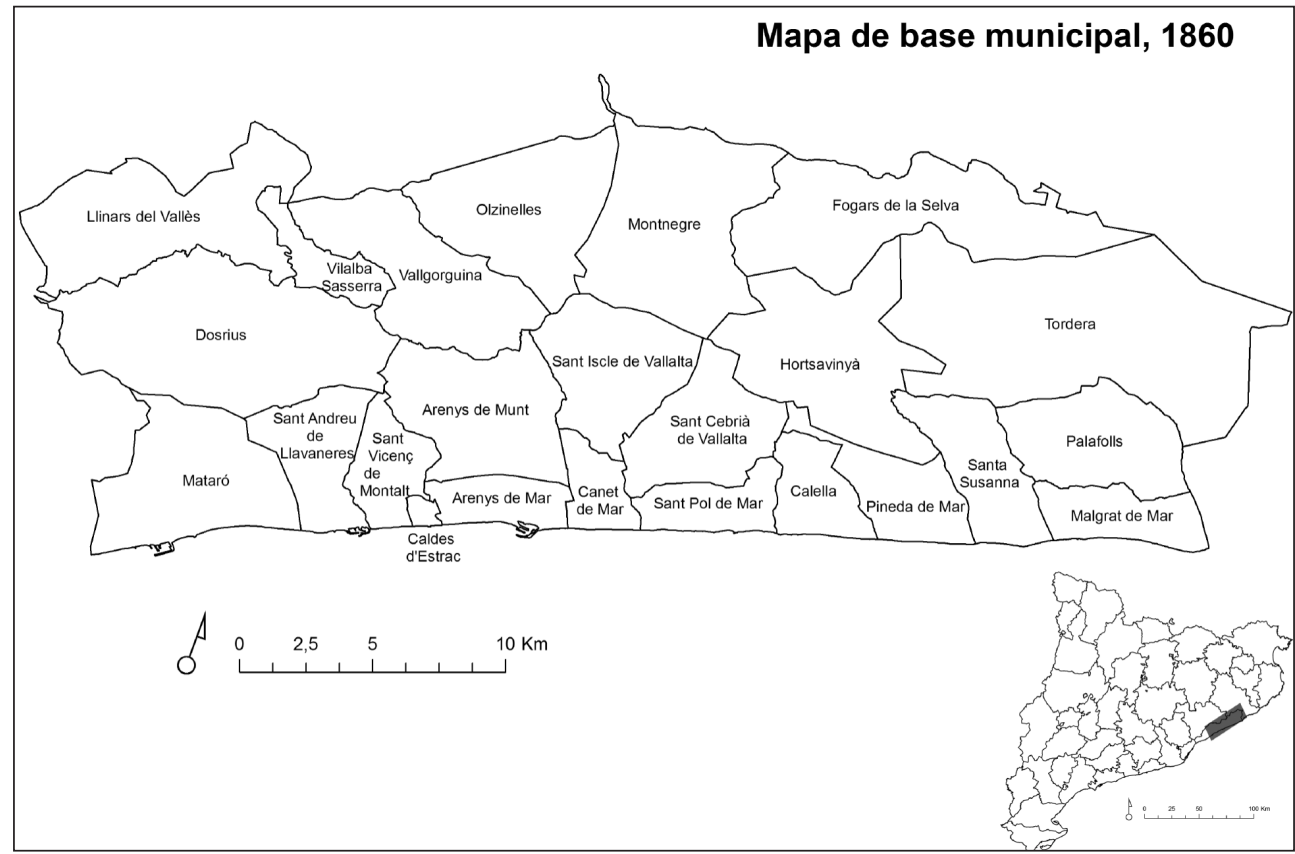

Fuente: Elaboración propia a partir del Nomenclátor de 1860.

Iscle de Vallalta (1853), Sant Pol de Mar (1853), Tordera (1853) y Vallgorguina (1853). En consecuencia, a finales de 1853 se contaba ya con una detallada planimetría catastral para más de la mitad de los municipios del sector montañoso del Montnegre-Corredor (figura 1).

El ciclo de renovación de los amillaramientos correspondiente al período 1858-1863 dio lugar a nuevas operaciones catastrales, que incluyeron nuevos trabajos planimétricos en Sant Cebrià de Vallalta (1858), Sant Pol de Mar (1861) y Arenys de Munt (1862). Considerando los elementos de comprobación de la riqueza territorial que tenía a su alcance la administración provincial de Hacienda, no constituye ninguna sorpresa que los amillaramientos reflejen con razonable fidelidad las superficies sometidas a explotación.

Una comparación sistemática para todos los municipios de la zona entre la superficie amillarada y la superficie geográfica muestra un bajo índice de ocultación absoluta de la propiedad (ver Anexo I). La superficie declarada en los amillaramientos de 1852 equivale al $86,3 \%$ de la superficie geográfica. Considerando que la superficie no amillarable debía ser importante en los municipios de la cuenca del Tordera, dada la amplitud del talweg del río, así como en los municipios costeros, dada la existencia de numerosas playas y arenales, la baja entidad de la ocultación aparente permite descartar la hipótesis de un fraude sistemático.

Cabe decir que, pese a todo, existen en algunos casos sensibles diferencias entre la extensión geográfica y la extensión declarada. Las desviaciones extremas corresponden a los municipios de Malgrat de Mar, con una ocultación aparente en 1852 del 50,5\%, y al muni- 
cipio de Palafolls, con una superficie declarada superior al 7,3\% a la superficie geográfica; se trata en ambos casos de amillaramientos formados antes de que estuviese disponible el levantamiento parcelario. Pues bien, estas desviaciones extremas fueron corregidas en los amillaramientos presentados en la década de 1860. En el amillaramiento correspondiente a 1862 Malgrat de Mar pasó a declarar unas propiedades rústicas equivalentes al 76,6\% de la superficie geográfica. En el caso de Palafolls, el amillaramiento del año 1862 registra una superficie declarada equivalente al 90,5\% del término municipal. Esta positiva rectificación presta un claro aval a la consistencia de la fuente.

Por otra parte, la gravedad de la crisis vitícola provocada por la difusión de la plaga del oidium a partir de 1852 originó la apertura de numerosos expedientes de reclamación de agravio por parte de los municipios (Nadal y Urteaga, 2008). La administración provincial de Hacienda respondió a las reclamaciones de agravio redoblando el control sobre los amillaramientos, y enviando comisiones de comprobación a los municipios del área de estudio. El resultado de las pruebas periciales realizadas por estas comisiones de comprobación no detecta, tal como se detallará a continuación, discrepancias de relieve ni para los usos del suelo ni para la valoración de la producción.

\section{EL ÁREA DE ESTUDIO}

La sierra de Montnegre-Corredor constituye un pequeño macizo montañoso (máxima altura 773 metros) situado en el sector central de la cadena Costera catalana, a unos 50 kilómetros al nordeste de Barcelona. El área de estudio, con una superficie aproximada de 400 kilómetros cuadrados, está limitada al norte y al oeste por el curso del río Tordera. En la parte central de la sierra el relieve es sinuoso y accidentado, con muy pocas zonas llanas aptas para el cultivo. Las rieras y torrentes han excavado estrechos valles sobre los terrenos graníticos, que se abren en dirección al Tordera o se precipitan hacia el Mediterráneo. Poblados bosques de pinos y alcornoques cubrían la mayor parte de esa zona, que actualmente es un parque natural. Hacia levante, la sierra finaliza en una estrecha zona costera, con óptimas condiciones para la actividad agraria.

A mediados del siglo XIX la superficie dedicada a uso forestal en el área del MontnegreCorredor superaba las 15.000 hectáreas: aproximadamente un 35\% de la superficie geográfica total. El dominio del bosque en la zona era claramente superior al registrado en el conjunto de la comarca del Maresme, y superaba también ligeramente al de algunas comarcas del interior, como el Vallès Oriental, que contenían importantes extensiones boscosas. La disposición y características de la cadena montañosa litoral desempeñan en este aspecto un papel crucial (figura 2).

En efecto, tanto la disposición de los asentamientos de población como la organización del espacio dimanaban de la configuración del relieve. La red urbana presentaba una característica disposición lineal. A partir de Mataró, y alineadas en la estrecha llanura costera, las villas marineras se sucedían hasta la desembocadura de la Tordera, separadas entre si a distancias escasamente superiores a los dos kilómetros. La vida económica de estas villas combinaba la pesca y el transporte marítimo con una intensa actividad agraria y manufacturera. La viña, y los cultivos hortícolas y frutales, tenían una marcada orientación comercial. Las fábricas de hilados y las manufacturas de géneros de punto daban empleo a cientos de 
Figura 2

BLOQUE DIAGRAMA DEL ÁREA DE ESTUDIO

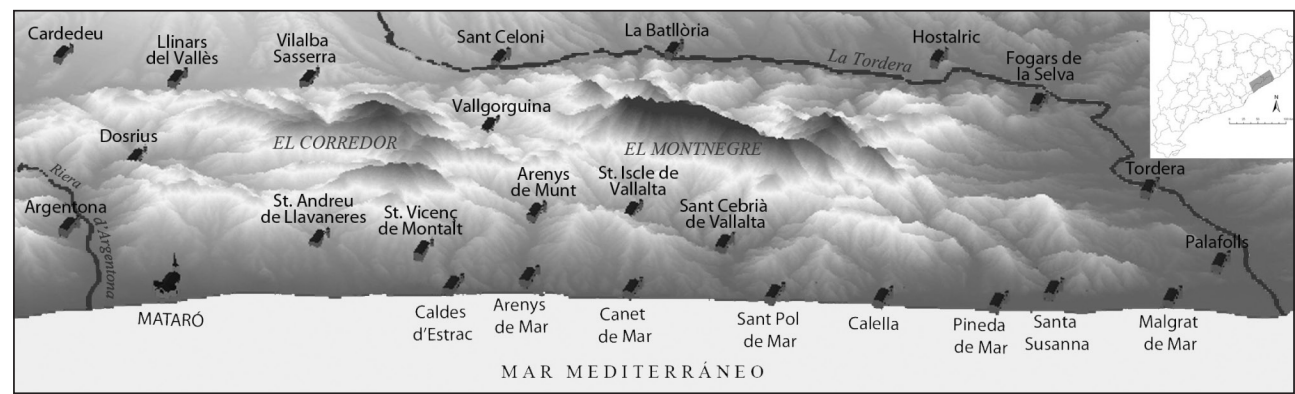

Fuente: Elaboración propia.

trabajadores. Junto a ello, la construcción naval, la industria del vidrio, la tonelería y la fabricación de tapones de corcho eran testigo de una incesante actividad manufacturera centrada en el aprovechamiento de los recursos de la montaña.

La orla de villas costeras tenía su paralelo en la sucesión de pueblos de dedicación esencialmente agraria y forestal alineados siguiendo el curso de la Tordera (de Llinars del Vallès a Tordera). Entre la depresión prelitoral y la costa tan sólo la riera de Argentona, las rieras de Arenys y Vallgorguina, y la riera de Vallalta ofrecen estrechos pasillos con espacios susceptibles de ser cultivados. En esos terrenos relativamente angostos, y aprovechando las laderas mejor insoladas para el cultivo de la vid, se encajarán los ejes transversales formados por las poblaciones de Arenys de Munt y Vallgorguina por un lado y Sant Iscle de Vallalta y Sant Cebrià de Vallalta por otro. Fuera de los valles y de la llanura costera, el relieve quebrado de los macizos del Montnegre y el Corredor reducían notablemente las posibilidades de la agricultura.

Ahora bien, el relieve montañoso, que limitaba la superficie cultivada, hacía, en cambio, que los bosques pudieran ocupar una extensión muy grande. Los montes maderables, los bosques de alcornoques, los bosques de carboneo e incluso los terrenos poblados de matorral, constituían elementos perfectamente delimitados para un aprovechamiento integral que era complementario de la actividad agraria y manufactura (figura 3 ).

Según las superficies declaradas en los amillaramientos, los bosques maderables ocupaban 3.600 hectáreas, de las cuales alrededor de 400 hectáreas estaban constituidas por plantaciones de álamos y olmos (Populus alba, Populus nigra y Ulmus minor), y 128 hectáreas eran castaños (Castanea sativa). Los bosques de alcornoques (Quercus suber) destinados a la producción de corcho totalizaban más de 1.100 hectáreas. Los montes dedicados a la producción de leña y carboneo cubrían una superficie mucho mayor (10.634 hectáreas), equivalente casi al $70 \%$ del bosque (ver tabla 1 ).

Dada la naturaleza fiscal de los amillaramientos es posible que las declaraciones tiendan a infravalorar la superficie de los bosques maderables y los dedicados a alcornocal (que soportaban una mayor presión tributaria), y a sobrevalorar la superficie dedicada a otros usos (que tributaban a un tipo más bajo). Una comprobación pericial realizada en el municipio de Sant Cebrià de Vallalta en 1862, a fin de verificar el amillaramiento presentado en 1859, 


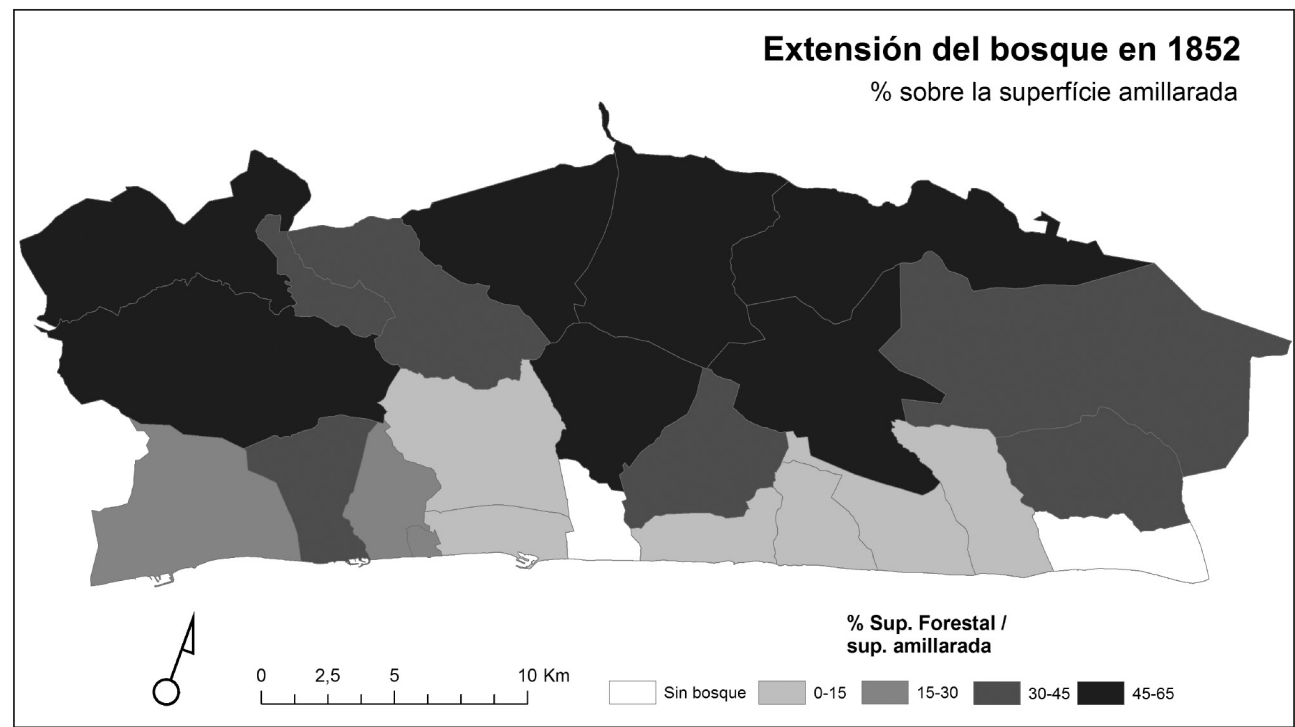

Fuente: Elaboración propia.

arrojó las siguientes desviaciones: los bosques de ribera y los de alcornoques estaban infravalorados en un $0,1 \%$, los bosques maderables en un $1,7 \%$, y los bosques de leña en el 4,3\%. Por el contrario, la superficie de las tierras yermas se había sobrevalorado en un $2,6 \%{ }^{2}$. Si los resultados obtenidos por la medición parcelaria de Sant Cebrià de Vallalta fuesen extrapolables al conjunto del área de estudio, las desviaciones por ocultación fiscal no llegarían a distorsionar la imagen global de los usos del suelo.

La estructura del poblamiento refleja asimismo la dualidad de la economía rural en el área del Montnegre-Corredor. Según el Nomenclátor de 1860 en la zona litoral, de elevada densidad de población, coexistían los tipos de doblamiento concentrado y disperso, pero con un claro predominio de la población agrupada en núcleos. En el área de montaña, por el contrario, predominaba de modo absoluto el poblamiento disperso. Los municipios de Fogars de Tordera (123 casas, 707 habitantes), Hortsavinyà (95 casas, 512 habitantes), Montnegre (83 casas, 503 habitantes) y Olzinellas (45 casas, 309 habitantes) tenían el carácter de partida rural, con un $100 \%$ de la población diseminada. Fogars de Tordera contaba con menos de cuatro casas diseminadas por cada 100 hectáreas de superficie municipal, Hortsavinyà con poco más de tres, Montnegre tenía 2,6 y Olzinellas 1,9. La población diseminada superaba el $60 \%$ en los términos de Dosrius, Vallgorguina, Sant Iscle de Vallalta y Sant Cebrià de Vallalta.

2 Expediente de rectificación sobre el terreno del de Comprobación en masa de la queja de Agravio producida por el Ayuntamiento y Junta Pericial de San Ciprián de Vallalta, 1862. Archivo de la Corona de Aragón, Hacienda, Ter 1.299. 
Tabla 1

DISTRIBUCIÓN DE LOS APROVECHAMIENTOS FORESTALES EN 1852

(Superficie en hectáreas)

\begin{tabular}{|c|c|c|c|c|c|c|c|}
\hline Municipios & \begin{tabular}{|c|}
$\begin{array}{c}\text { Árboles de } \\
\text { ribera }\end{array}$ \\
\end{tabular} & Castaños & $\begin{array}{c}\begin{array}{c}\text { Alcorno- } \\
\text { ques }\end{array} \\
\end{array}$ & \begin{tabular}{|c|}
$\begin{array}{c}\text { Bosque } \\
\text { maderable }\end{array}$ \\
\end{tabular} & $\begin{array}{c}\begin{array}{c}\text { Bosque de } \\
\text { fagina }\end{array} \\
\end{array}$ & \begin{tabular}{|c|}
$\begin{array}{c}\text { Superficie } \\
\text { forestal }\end{array}$ \\
\end{tabular} & \begin{tabular}{|c|} 
Superficie \\
amillarada
\end{tabular} \\
\hline Arenys de Mar & & & & & 38 & 38 & 482 \\
\hline Arenys de Munt & & 42 & & & 43 & 85 & 1.486 \\
\hline Caldes d'Estrac & & & & & 11 & 11 & 54 \\
\hline Calella & & & & & 13 & 13 & 405 \\
\hline Canet de Mar & & & & & & 0 & 618 \\
\hline Dosrius & 13 & & & 780 & 1.598 & 2.391 & 3.722 \\
\hline Fogars de Tordera & 81 & 8 & 167 & 335 & 1.252 & 1.843 & 2.974 \\
\hline Hortsavinyà & & 11 & 90 & 150 & 619 & 870 & 1.852 \\
\hline Llinars del Vallès & & & & 363 & 1.086 & 1.449 & 2.508 \\
\hline Malgrat de Mar & & & & & & 0 & 447 \\
\hline Mataró & & & & & 452 & 452 & 1.993 \\
\hline Montnegre & 37 & 55 & 70 & 392 & 1.065 & 1.619 & 2.880 \\
\hline Olzinellas & 9 & 12 & 197 & 113 & 777 & 1.108 & 2.209 \\
\hline Palafolls & 84 & & 72 & 137 & 272 & 565 & 1.758 \\
\hline Pineda de Mar & & & & & 48 & 48 & 783 \\
\hline S. Andreu de Llavaneres & & & & & 370 & 370 & 994 \\
\hline Sant Cebrià de Vallalta & 21 & & 10 & 38 & 421 & 490 & 1.347 \\
\hline Sant Iscle de Vallalta & & & 54 & 97 & 680 & 831 & 1.678 \\
\hline Sant Pol de Mar & 20 & & & & & 20 & 607 \\
\hline Sant Vicenç de Montalt & & & & & 141 & 141 & 779 \\
\hline Santa Susanna & & & & 14 & 104 & 118 & 1.073 \\
\hline Tordera & 126 & & 333 & 323 & 1.106 & 1.888 & 5.050 \\
\hline Vallgorguina & 14 & & 109 & 376 & 392 & 891 & 2.006 \\
\hline Vilalba Sasserra & & & & & 146 & 146 & 444 \\
\hline Total & 405 & 128 & 1.102 & 3.118 & 10.634 & 15.387 & 38.149 \\
\hline
\end{tabular}

Fuente: Elaboración propia a partir de los amillaramientos de Arenys de Mar (1852); Arenys de Munt (1851); Caldes d'Estrac (1857); Calella (1851); Canet de Mar (1853); Dosrius (1853); Fogars de Tordera (1854); Hortsavinyà (1854); Llinars del Vallès (1852); Malgrat de Mar (1851); Mataró (1851); Montnegre (1853); Olizinellas (1851); Palafolls (1853); Pineda de Mar (1852); Sant Andreu de Llavaneres (1857); Sant Cebrià de Vallalta (1853); Sant Iscle de Vallalta (1850); Sant Pol de Mar (1852); Sant Vicenç de Montalt (1853); Santa Susanna (1853); Tordera (1858); Vallgorguina (1854) y Vilalba Sasserra (1851). Archivo de la Corona de Aragón. Sección Hacienda.

Así pues, en los altiplanos de las sierras del Corredor y el Montnegre, y en la vertiente orientada al Vallès de la cadena montañosa, las masías, con sus labradíos de cereal, aparecían como islas en el bosque, conectadas entre sí por una tenue red de caminos de montaña. En la llanura aluvial, una tupida red de villas asomadas al mar dejaba a sus espaldas un paisaje de huertas, viñedos y tierras de labor. Allí las masas de vegetación arbórea habían quedado 
reducidas a unas pocas islas de verdor emergiendo entre poblaciones y labradíos: pinares plantados en tierras marginales para el cultivo, y pequeños bosques de ribera en las umbrías y fondos de las rieras.

\section{CARACTERIZACIÓN DEL ESPACIO FORESTAL}

Las fuentes utilizadas no permiten identificar unidades de carácter ecológico. La documentación describe los aprovechamientos que tienen un distinto tipo de gravamen fiscal. Los aprovechamientos de carácter forestal se designan en los amillaramientos del modo siguiente: «alamedas», «castaños», «alcornoques» (o bosques a corcho), «bosques de construcción» (o bosques de madera) y «bosques de fagina». Se trata, como es obvio, de áreas de explotación en las que se aprovecha una especie arbórea dominante o un conjunto de especies arbóreas y arbustivas asociadas.

En la década que media entre 1852 y 1862 las masas de arbolado no experimentaron variaciones sensibles (ver tabla 2). La superficie dedicada a los bosques de ribera y a sotos de castaños se incrementó ligeramente, lo que puede indicar tanto un incremento en las plantaciones como una mayor precisión en los amillaramientos. La ligera reducción superficial de los bosques maderables queda ampliamente compensada por la ampliación de los alcornocales y los bosques de carboneo. La única modificación de importancia se produce en la ampliación substancial de las tierras declaradas como yermo: casi un 30\% en una sola década. La crisis vitícola provocada por la difusión de la plaga del oidium en la década de 1850 explica esta súbita expansión de los yermos. Entre 1852 y 1862 el oidium destruyó más de 3.500 hectáreas de viñedo en la zona del Montnegre-Corredor (Nadal y Urteaga, 2008), que pasaron a ser declaradas como tierras yermas en los amillaramientos realizados a partir de 1858.

En algunos tipos de aprovechamiento forestal las especies arbóreas están claramente individualizadas en la documentación fiscal, de modo que las áreas de aprovechamiento dominante pueden asociarse con unidades paisajísticas. En la documentación conexa a los amillaramientos las alamedas se describen como plantaciones de álamos y olmos, con turnos de corta de entre 20 y 30 años ${ }^{3}$. Entre los gastos de explotación se consignan los jornales de plantación, y los costes de canalización de las rieras y arreglo de los márgenes. No pueden caber dudas de que estamos ante bosques de ribera, objeto de plantación y cuidado sistemático, con poblaciones de álamos (Populus alba), chopos (Populus nigra) y olmos (Ulmus minor). Los «bosques de corcho» constituyen, según la documentación fiscal, «plantaciones de alcornoques para utilizar el corcho». Por último, los «castaños» son, literalmente, plantaciones de castaños, de los que se explota el fruto y la madera.

Mayor dificultad ofrece la caracterización de las áreas identificadas como bosques a fagina y bosques de madera (o de construcción). A diferencia de los casos citados anteriormente, que tenían el carácter de bosques de cultivo, los bosques maderables y los bosques de carboneo constituían explotaciones seculares del monte originario, que con toda seguridad

3 Expediente de reclamación presentado por el pueblo de San Pol de Mar, 1861, Archivo de la Corona de Aragón, Hacienda, Inv. 1-983. Ver también Expediente de rectificación... de San Ciprián de Vallalta, 1862. Archivo de la Corona de Aragón, Ter 1.299. 
había atravesado ya sucesivas fases de alteración. Unas veces podía tratarse del aprovechamiento de las especies originarias del bosque esclerófilo (característico de las solanas en todo el macizo del Montnegre-Corredor), o del bosque caducifolio, típico de las umbrías del Montnegre. En otros casos podría tratarse de la explotación del bosque en su etapa regresiva de matorral, con las mismas especies arbóreas y arbustivas u otras de carácter subserial. Desgraciadamente, las fuentes primarias manejadas son opacas en este punto, y habrá que recurrir a inferencias indirectas. A continuación se trata, con el detalle posible, la distribución de los distintos tipos de bosque.

Los bosques de ribera, denominados alamedas, se localizaban, al igual que hoy, en las umbrías, en los fondos de las rieras y a lo largo de la cuenca de la Tordera. En los amillaramientos se declaran extensiones significativas de alamedas en el término de Dosrius (riera de Argentona), en los términos de Sant Iscle y Sant Cebrià de Vallalta (riera de Vallalta), y en todos los municipios regados por la Tordera. Las extensiones más importantes se daban en Fogars de Tordera (81 hectáreas declaradas), Tordera (126 hectáreas) y Palafolls (84 hectáreas).

Tabla 2

DISTRIBUCIÓN DE LA SUPERFICIE FORESTAL EN EL MONTNEGRE-CORREDOR

\begin{tabular}{|l|r|r|r|r|}
\hline & \multicolumn{2}{|c|}{$\mathbf{1 8 5 2}$} & \multicolumn{2}{c|}{$\mathbf{1 8 6 2}$} \\
\hline & Hectáreas & \multicolumn{1}{c|}{$\%$} & Hectáreas & \multicolumn{1}{c|}{$\%$} \\
\hline Árboles de ribera & 405 & 2,6 & 421 & 2,6 \\
\hline Castaños & 128 & 0,8 & 177 & 1,1 \\
\hline Alcornoques & 1.102 & 7,2 & 1.144 & 7,1 \\
\hline Bosque maderable & 3.118 & 20,3 & 2.933 & 18,3 \\
\hline Bosque de leña & 10.634 & 69,1 & 11.387 & 70,9 \\
\hline Total & 15.387 & 100,0 & 16.082 & 100,0 \\
\hline \% Área forestal/Superficie amillarada & & 41,5 & & 42,1 \\
\hline
\end{tabular}

Fuente: Elaboración propia a partir de Tabla 1.

Las especies consignadas en estos bosques de plantación eran álamos (Populus alba y Populus nigra) y olmos (Ulmus minor). Es muy posible que apareciesen también especies de crecimiento vigoroso, como el sauce (Salix balilonica), cuya madera se asemeja a la del álamo. Olmos y álamos se empleaban como madera de construcción (para vigas), y también para hacer tablazón. La madera de olmo tenía utilidad especial para la fabricación de ejes y ruedas de carros.

La extensión del castaño (Castanea sativa) en la zona debe considerarse también producto de la acción deliberada del hombre. Del castaño se aprovechaba su fruto, las varas arbustivas (para la fabricación de estacas y postes para cercas), y la madera. La madera de castaño, suave y fácil de trabajar, se empleaba generalmente para la fabricación de los barriles dedicados al envasado de la pesca en salazón. La demanda de este tipo de recipientes era muy abundante en los puertos pesqueros, de ahí la presencia de sotos de castaños en un área ecológicamente subóptima para el desarrollo de esta especie. 
La utilización preferente de la madera de castaño para la fabricación de barriles para salazón puede haber influido en la localización de los sotos. Tan sólo cinco municipios declaran disponer de extensiones significativas de castaños: Arenys de Mar, Fogars de Tordera, Hortsavinyà, Montnegre y Olzinellas. Sin embargo, las concentraciones de verdadera importancia se dan en Montnegre (55 hectáreas) y Arenys de Munt (96 hectáreas en 1862). La carretera construida por la Diputación de Barcelona, a mediados del siglo XIX, desde Arenys de Mar a Sant Celoni facilitaba el acarreo de madera desde los sotos de Arenys de Munt (y del Montnegre) hasta la costa. El geógrafo Salvador Llobet $(1955,292)$ registra, casi un siglo más tarde, un patrón similar de distribución de los castaños: 100 hectáreas en Arenys de Munt (en 1944), y 25 hectáreas en Tordera, que por entonces había asimilado ya el término municipal de Hortsavinyà.

El bosque esclerófilo es la comunidad vegetal climácica en las vertientes soleadas de toda la cadena litoral catalana. En su formación orginaria, el estrato arbóreo de este bosque perennifolio se compone esencialmente de encinas (Quercus ilex) y alcornoques (Quercus suber). El sotobosque ofrece estratos arbustivos con una gran variedad de especies, entre las que suelen figurar brezo (Erica arborea), carrasca (Quercus coccifera), madroño (Arbutus unedo), durillo (Viburum tinus) y lentisco (Pistacea lentiscos). La explotación secular de los montes del Montnegre-Corredor debió originar una transformación profunda tanto del bosque como del sotobosque. En concreto, la fuerte demanda de corcho, impulsada por la industria corcho-taponera desde finales del siglo XVIII, favoreció la extensión del alcornocal, en detrimento del encinar, en las áreas de condiciones edáficas y climácicas más favorables para el Quercus suber. Paralelamente, las plantaciones de pinos (Pinus pinea y Pinus halepensis), de mayor utilidad que la encina como maderas de construcción, colonizaron una parte de los antiguos encinares.

El mapa de los bosques de alcornoques a mediados del siglo XIX presenta una distribución característica (ver figura 4). Las más de 1.100 hectáreas declaradas como «bosques de corcho» aparecen casi exclusivamente en los términos municipales correspondientes a la sierra del Montnegre, siendo las excepciones los términos de Vallgorguina y Vilalba Sasserra. En cinco municipios las extensiones de alcornocales superan las 100 hectáreas, sumando en conjunto un $75 \%$ del área dedicada a este aprovechamiento. Se trata de los municipios de Tordera (333 hectáreas), Olzinellas (197 hectáreas), Fogars de Tordera (167 hectáreas) y Vallgorguina (109 hectáreas). El contraste entre la ausencia de bosques de alcornoques en el macizo del Corredor, y su densa presencia en el macizo del Montnegre resulta llamativa, pero no inverosímil. La abundancia de Quercus suber en el Montnegre se explica por la combinación de suelos silíceos con una cierta humedad. Esta última condición se da en menor grado en la sierra del Corredor (cf. Llovet, 1955; y Gómez, Mateu y Fernández, 1985).

Aparecen registradas en los amillaramientos unas 3.000 hectáreas de bosques maderables (figura 5). Los montes arbolados cubrían los municipios del macizo del Montnegre y del Corredor, aunque presentan un mayor desarrollo en este último macizo (ver figura 5). En la sierra del Corredor sobresalían las extensiones arboladas de los términos de Dosrius (780 hectáreas), Llinars del Vallès (363 hectáreas) y Vallgorguina (376 hectáreas). En la sierra del Montnegre destacaban los bosques arbolados de los municipios enclavados en su vertiente vallesana: Montnegre (393 hectáreas), Fogars de Tordera (335 hectáreas), y Tordera (323 hectáreas). 


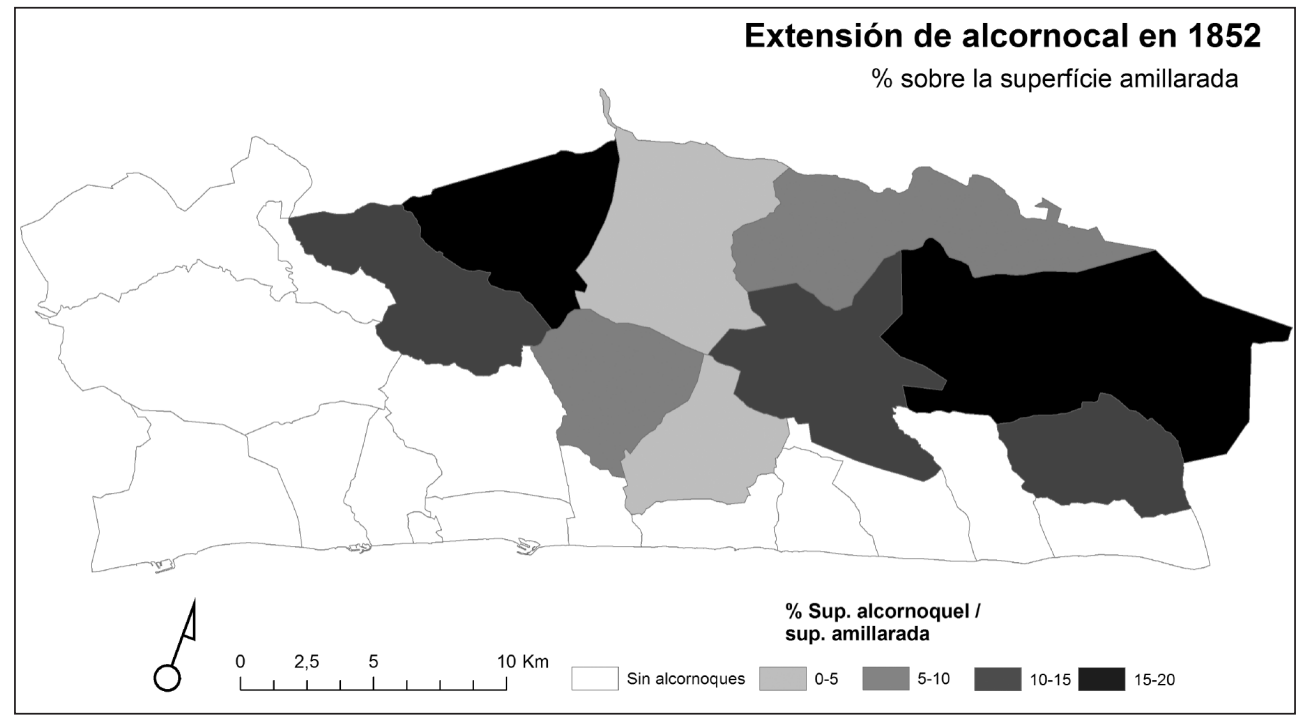

Fuente: Elaboración propia.

Desgraciadamente, los amillaramientos no aportan ninguna información de relieve respecto a la composición florística de tales montes maderables. En la Estadística del Comercio de Cabotaje se consigna la salida de maderas de encina, pino y roble por los puertos de Arenys de Mar y Malgrat (amén de maderas de álamo y olmo que se obtenían, fundamentalmente, en los bosques de ribera). Atendiendo a la distribución actual de los principales mantos de vegetación, se podría inferir que los robles procedían, esencialmente, de las umbrías del macizo del Montnegre, donde se da una abundante presencia del bosque caducifolio. Los pinos y encinas tienen actualmente una presencia ubicua tanto en el Montnegre como en el Corredor, y quizá era así también a mediados del ochocientos. Sin embargo, nada seguro podemos decir sobre esta cuestión.

Una cosa si es segura. Los bosques del Montnegre-Corredor se habían alejado de su formación climácica hacía ya mucho tiempo. En su formación originaria el monte arbolado presenta dificultades para el aprovechamiento forestal. La riqueza del estrato arbustivo de los bosques mediterráneos dificulta la circulación y la saca de troncos. La explotación maderera requiere la construcción de caminos, la roza del matorral y la corta selectiva. En los claros abiertos en el bosque se practicaba el carboneo desde tiempo inmemorial. Los montes maderables estaban transformados tanto en su vuelo como en su suelo.

Los bosques de leña, denominados habitualmente en los amillaramientos «bosques de fagina», cubrían más de 10.000 hectáreas. Se trata, con mucho, del mayor de los aprovechamientos, ya que suponía un $44 \%$ de la superficie forestal, y casi un $28 \%$ de la superficie total amillarada. Los bosques dedicados a leña aparecen en prácticamente todos los términos municipales de la zona: las únicas excepciones son los municipios costeros de Canet de Mar, 
Figura 5

ÁREA DESTINADAA LA PRODUCCIÓN DE MADERA. EN PORCENTAJE SOBRE LA SUPERFICIE AMILLARADA

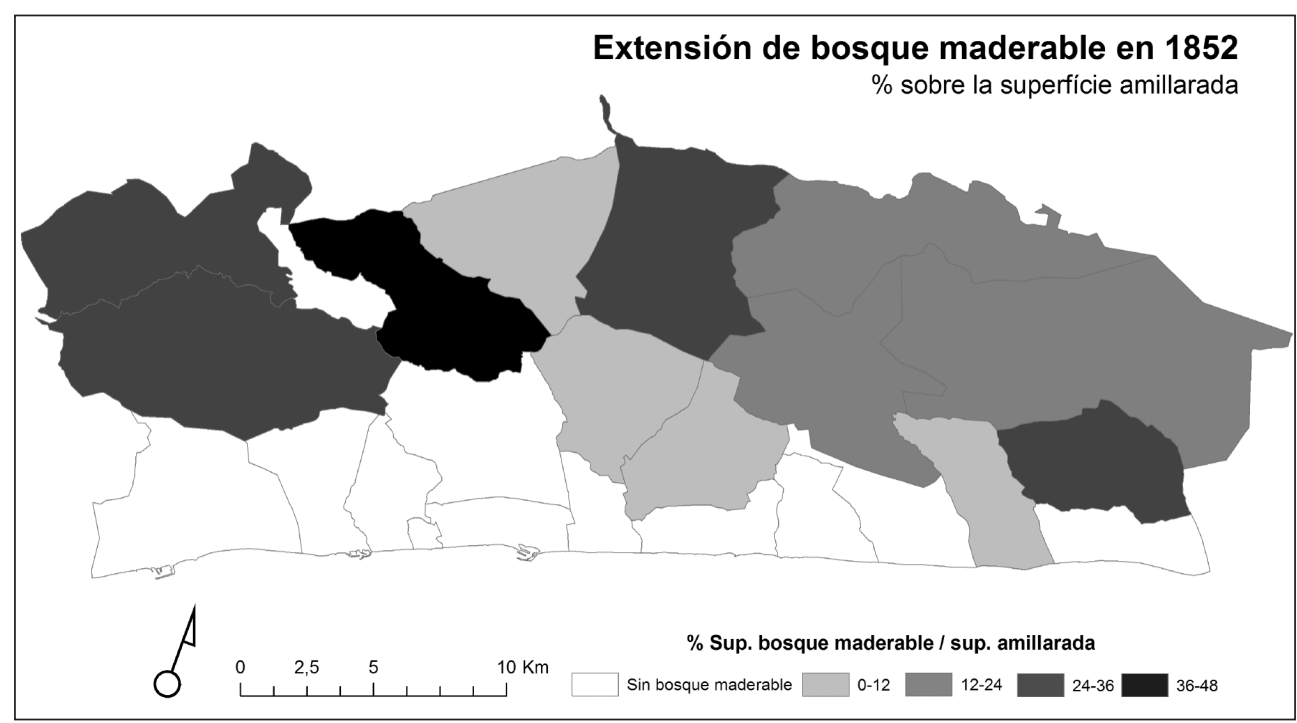

Fuente: Elaboración propia.

Malgrat de Mar y Sant Pol de Mar, los tres de reducida extensión superficial. Las mayores extensiones de bosques de leña se daban en Dosrius (1.598 hectáreas), Llinars del Vallès (1.086 hectáreas), Montnegre (1.065 hectáreas), Fogars de Tordera (1.252 hectáreas) y Tordera (1.106 hectáreas).

La distinción fiscal entre montes maderables y montes de leña era clara. En los primeros la leña gruesa era un subproducto de la tala. En los segundos la leña constituía el único aprovechamiento. La distinción geográfica entre bosques maderables y bosques de leña no podía ser tan clara. En los bosques reales la transición entre arboledas densas y arboledas ralas suele ser progresiva. Tampoco resulta fácil trazar una frontera neta entre las arboledas ralas y el dominio del matorral con árboles aislados. La fuente utilizada, sin embargo, no permite matizaciones de este tipo.

Los bosques de leña eran montes tallares de leña y carboneo. En ellos se aprovechaba el matorral, determinadas especies arbustivas como el brezo (Erica arborea) y la carrasca (Quercus coccifera), y, sobre todo, las cepedas de robles y encinas. Una vez talados, los tocones de robles y encinas revenaban formando matas de varios metros de altura. Tales matas, fáciles de cortar, se talaban en turnos de 5 a 15 años. La leña podía carbonizarse en el mismo bosque para la obtención de carbón vegetal, o agavillarse («afaginarse») para su venta en el mercado.

\section{LOS APROVECHAMIENTOS FORESTALES}

A mediados del siglo XIX los montes del área del Montnegre-Corredor se explotaban en régimen de propiedad privada. No hemos encontrado, en la documentación consultada, señal 
alguna de propiedad comunal, ni tampoco indicios de servidumbres colectivas en el bosque. Los estudios de Salvador Llobet sobre la zona indican que la propiedad privada estaba ya plenamente asentada en el siglo XVIII (Llobet, 1955, 248).

Resulta bastante difícil realizar un cálculo, ni siquiera aproximado, acerca del alcance de la actividad forestal en términos de producción y empleo. Una cosa si resulta clara: la producción forestal constituía una de las bases económicas de la comarca.

El rendimiento estimado de los bosques de ribera, con un turno de corta de 30 años, era de 40 árboles por hectárea ${ }^{4}$. Los costes de plantación se estimaban en un jornal por cada 30 árboles plantados, es decir, aproximadamente, 1,3 jornales por hectárea reforestada. Si las estimaciones realizadas por la comisión evaluadora enviada por la Administración de Hacienda en 1862 fuesen ajustadas, la producción total de los bosques de ribera del área de estudio vendría a ser entre 16.000 y 17.000 árboles anuales.

Por su extensión, y por la importancia de sus aprovechamientos, los bosques de alcornoques tenían una gran significación en la economía de la zona. La leña del sotobosque y las ramas de los alcornoques se empleaban para combustible. Las hierbas y las bellotas como pasto estacional. Las cortezas constituían, como es lógico, la explotación principal: el corcho en bruto se empleaba tradicionalmente, por su flotabilidad, para la fabricación de artes de pesca. A mediados del siglo XIX su principal destino era ya la manufactura de tapones de corcho. El elevado precio de los panes de corcho, unido a su liviano peso y a la proximidad de las industrias transformadoras, hacían del corcho un producto altamente rentable y netamente comercial.

La pela de los alcornoques se realizaba entre los meses de junio y agosto (Palomer, 1996, 41). El rendimiento anual estimado era de 35 docenas de panes de corcho (de cuatro palmos de largo por dos de ancho) por hectárea. El precio de venta de los panes oscilaba entre $10 \mathrm{y}$ 12 pesetas la docena. Los costes de explotación (pela, desembosque y transporte) sumaban unas 3,5 pesetas por docena de panes, de modo que el producto neto por hectárea podía superar con facilidad las 250 pesetas anuales, sólo en corcho ${ }^{5}$. A efectos de comparación puede ser útil señalar que el salario de un jornalero era por entonces de siete reales al día, de modo que el producto líquido de una hectárea de alcornocal equivaldría a algo más de 140 jornales. Se trata de una utilidad superior a la de cualquier otro tipo de aprovechamiento forestal, con la excepción de los bosques de ribera.

El rendimiento de los montes arbolados de Sant Cebrià de Vallalta se estimó, en 1862, en 10 árboles anuales por hectárea ${ }^{6}$. El turno de corta era de 50 años, y los precios por árbol oscilaban entre 7 y 14 pesetas. Es muy posible, sin embargo, que el rendimiento ofrecido por los montes arbolados de este municipio no fuera representativo del conjunto de la producción forestal de la zona: los bosques de Sant Cebrià de Vallalta debían carecer, casi por completo, de robles (Quercus petraea). El bosque esclerófilo no ofrece la misma producción que el bosque caducifolio, y los precios de la madera de roble eran muy distintos de los de la madera de pino y encina.

\footnotetext{
4 Expediente de rectificación... de San Ciprián de Vallalta, 1862. ACA, Ter 1.299.

5 Ibidem.

6 Ibidem.
} 
Es preciso añadir que los árboles no constituían el único aprovechamiento de los bosques maderables, ni siquiera el principal en términos económicos. Además de la obtención de troncos destinados a la construcción o a los aserraderos, los bosques arbolados se aprovechaban para el acopio de leña y la producción de carbón vegetal. El rendimiento en leña de los bosques maderables se estimaba en 50 quintales anuales de leña gruesa por hectárea y 40 cargas adicionales de «fagina para los hornos». La carga de leña se vendía a dos pesetas. Los costes de explotación eran elevados: dos reales por el corte de cada carga; 1,50 reales por los trabajos de desembosque y tres reales adicionales por el transporte hasta el mercado. En total, el coste de producción y transporte suponía alrededor del un $80 \%$ del precio final.

La producción de los bosques de «fagina» variaba notablemente de unos lugares a otros, en función del terreno y de las especies explotadas. En Sant Cebrià de Vallalta se declaraba un rendimiento anual de 75 cargas por hectárea y año, con un turno de corta de cinco años. En Sant Pol de Mar el turno de corta era de 13 años. El Ayuntamiento de Sant Pol de Mar declaraba unos rendimientos de 33 cargas de leña por cuartera (aproximadamente 110 cargas por hectárea). La inspección enviada por la Administración de Hacienda para rectificar el amillaramiento no se avino a este cálculo. La cuestión se resolvió del siguiente modo, según el informe firmado por el comisionado de Estadística Veremundo Surroca:

«Habiendo solicitado las corporaciones municipales [de Sant Pol de Mar] que se hiciese una prueba práctica para demostrar que los bosques de fagina de este país no producen por medio más de 33 cargas de leña cada 13 años, la Comisión ha aceptado dicha prueba. En su consecuencia, el agrimensor de esta Comisión [Tomás Soler] ha elegido y medido el trozo de bosque que ha conceptuado más a propósito para dicha prueba. Cortada y afaginada la leña en presencia del Comisionado [Veremundo Surroca], el agrimensor agregado a la comisión, el alcalde y un individuo de la junta pericial, dio razón de 36 cargas por cuartera» ${ }^{7}$. La prueba citada se realizó el 13 de agosto de 1861, y fue aceptada por el Ayuntamiento de Sant Pol.

En definitiva, la explotación de los bosques garantizaba combustible y materias primas para el consumo local, tanto de carácter doméstico como industrial. Por añadidura, la comercialización de productos forestales era, junto a la comercialización del vino, una de las principales actividades exportadoras de la zona. Las evidencias que pueden obtenerse del análisis de la Estadística del Comercio de Cabotaje para los años centrales del ochocientos son bastante concluyentes. Los puertos de Mataró, Arenys de Mar y Malgrat eran exportadores netos de productos forestales. En conjunto, en el período que media entre 1857 y 1859, el tráfico de este género de productos suponía casi un $40 \%$ de las mercancías comerciadas, y, atendiendo al peso, más del $70 \%$ de las exportaciones.

Se ha calculado la media anual para un período de tres años (1857-59), con el fin de compensar las fuertes oscilaciones anuales del tráfico. El intervalo elegido pretende ser representativo de la situación en la primera mitad del siglo XIX. La línea férrea entre Arenys de Mar y Tordera se tendió precisamente en los años arriba citados, pero no estuvo operativa antes de 1859. Por otra parte, dada la naturaleza de los productos forestales, y el elevado coste del transporte ferroviario en la época, es muy poco probable que se transportasen en tren.

7 Expediente de reclamación presentado por el pueblo de Sant Pol de Mar, 1861. Archivo de la Corona de Aragón, Hacienda, Inv. 1-983, fol. 120. 
La función comercial de los puertos antes citados no era idéntica. Mataró era, sobre todo, un puerto de entrada para alimentos y manufacturas, con unas salidas que no llegaban a compensar las mercancías desembarcadas. Aún así, el comercio de productos forestales constituía una rúbrica nada despreciable de su actividad portuaria. Mataró era importador neto de cortezas de pino, y exportador neto de maderas (ver tabla 3). Arenys de Mar presentaba una balanza comercial mucho más equilibrada. Las importaciones principales eran aceite y granos. Las exportaciones estaban presididas por el vino, las vasijas de barro y los productos forestales. Las exportaciones de madera desde Arenys de Mar suponían más de 17.000 quintales anuales. Las salidas de leña y carbón vegetal presentaban igualmente cifras medias de mucha consideración. Malgrat, por último, era un puerto esencialmente de salida, en el que las exportaciones triplicaban, en peso y valor, a las importaciones. La rúbrica principal de las mercancías embarcadas en Malgrat era la madera: casi 70.000 quintales de media anual en el período 1857-59. Le seguían en importancia el carbón vegetal (24.000 quintales), y la leña (2.449 quintales).

Tabla 3

TRÁFICO DE PRODUCTOS FORESTALES EN LOS PUERTOS DE MATARÓ, ARENYS DE MAR Y MALGRAT. COMERCIO DE CABOTAJE: MEDIA ANUAL DEL PERÍODO 1857-59

(Peso en quintales)

\begin{tabular}{|l|l|r|r|r|}
\hline \multicolumn{1}{|c|}{ Puerto } & \multicolumn{1}{|c|}{ Productos } & Entradas & \multicolumn{1}{c|}{ Salidas } & \multicolumn{1}{c|}{ Total } \\
\hline Mataró & Madera & 433 & 1.650 & 2.083 \\
\cline { 2 - 5 } & Corteza de pino & 692 & 0 & 692 \\
\hline \multirow{4}{*}{ Arenys de Mar } & Madera & 4.492 & 17.202 & 21.694 \\
\cline { 2 - 5 } & Leña & 0 & 3.000 & 3.000 \\
\cline { 2 - 5 } & Carbón vegetal & 0 & 1.055 & 1.055 \\
\cline { 2 - 5 } & Corcho & 0 & 182 & 182 \\
\hline \multirow{5}{*}{ Malgrat } & Madera & 340 & 69.430 & 69.770 \\
\cline { 2 - 5 } & Leña & 0 & 2.449 & 2.449 \\
\cline { 2 - 5 } & Carbón vegetal & 0 & 24.189 & 24.189 \\
\cline { 2 - 5 } & Piñas & 0 & 185 & 185 \\
\cline { 2 - 5 } & Corteza de encina & 0 & 20 & 20 \\
\cline { 2 - 5 } & Corteza de pino & 0 & 1.372 & 1.372 \\
\cline { 2 - 5 } & Ceniza & 5.957 & 120.751 & 126.708 \\
\hline & Total & $4 \%$ & $71 \%$ & $38 \%$ \\
\cline { 2 - 5 } & $\%$ sobre el tráfico total & & & 17 \\
\hline
\end{tabular}

Fuente: Elaboración propia a partir de la Estadística General del Comercio de Cabotaje, 1857-1859.

El acopio de cenizas (para la fabricación de jabón), de cortezas de pino y encina (empleadas en las tenerías como curtientes), y de piñas (utilizadas presumiblemente como combustible doméstico), era algo secundario considerando su valor económico, pero revelador de las características de la economía rural de la época: los bosques del Montnegre-Corredor fueron objeto de un aprovechamiento minucioso. Ninguna producción potencial, por modesta que en apariencia fuese, podía ser dejada de lado. La proximidad de los puertos de Mataró, 
Arenys de Mar y Malgrat al área forestal reforzaba las oportunidades de comercialización para un tipo de productos de escaso valor unitario, y por tanto muy sensibles a los costes del acarreo terrestre. Con todo, como es natural, los principales aprovechamientos forestales estaban constituidos por la madera y los productos combustibles. A ellos nos referiremos a continuación.

La madera constituía tanto un importante producto de exportación como la materia prima esencial de varias manufacturas locales. Disponemos de una relación bastante pormenorizada de las maderas exportadas a través del puerto de Malgrat en el año 1857 (ver tabla 4): Malgrat era el principal puerto exportador de madera de la zona, y en ese año salieron casi 69.000 quintales. La relación incluye once artículos diferentes, producto de distintas especies forestales.

La mercancía principal, con diferencia, eran los aros y duelas para pipería, que representaban el 60\% de las salidas. Las mejores duelas eran de madera de roble (Quercus robur y Quercus petraea), hendida y curada. Los toneles fabricados con roble no sólo conservaban el vino, sino también los vapores volátiles, que en recipientes de menor calidad se evaporarían con facilidad.

A la madera para pipería le seguía en importancia la tablazón de pino y chopo, y la madera para carros. En la fabricación de carros y carruajes se empleaba madera de muy diversas especies. Para la pieza central de las ruedas era esencial la madera de olmo, debido a su dureza y su resistencia a la fractura. Los radios de las ruedas solían hacerse de roble. Los elementos principales de la armazón del carro podían fabricarse con madera de roble o de fresno, recurriéndose al olmo y al álamo para las tablas laterales.

Tabla 4

MADERAS EMBARCADAS EN EL PUERTO DE MALGRAT (1857)

\begin{tabular}{|c|c|c|}
\hline Clases de madera & $\begin{array}{c}\text { Peso } \\
\text { (Quintales) }\end{array}$ & $\%$ \\
\hline Aros & 29.549 & 43,0 \\
\hline Duelas para pipería & 18.790 & 27,3 \\
\hline Tablas de pino y chopo & 7.079 & 10,3 \\
\hline Madera para carros & 4.118 & 6,0 \\
\hline Lata de chopo & 3.144 & 4,6 \\
\hline Madera para sillas & 2.249 & 3,3 \\
\hline Cuadrados & 1.723 & 2,5 \\
\hline Barras de encina & 995 & 1,4 \\
\hline Durmientes para ferrocarril & 520 & 0,8 \\
\hline Vigas de chopo & 500 & 0,7 \\
\hline Filetes de pino & 60 & 0,1 \\
\hline Total & 68.727 & 100,0 \\
\hline
\end{tabular}

Fuente: Elaboración propia a partir de la Estadística General del Comercio de Cabotaje, 1857. 
Además de los artículos citados se exportaban discretas cantidades de productos de chopo, pino y encina, maderas todas ellas abundantes en los bosques del Montnegre-Corredor. Vale la pena señalar, aunque por su volumen tenga un carácter casi anecdótico, el embarque de traviesas para ferrocarril, justamente en el momento en que se procedía a la construcción de la vía férrea desde Mataró a Tordera.

La investigación realizada por Maria Teresa Mola (1996) sobre las «Patentes de Sanidad» de Malgrat de Mar para el período que media entre 1868 y 1886 nos informa respecto al destino de los productos forestales embarcados en Malgrat. Las Patentes de Sanidad eran el documento con el que se garantizaba la ausencia de enfermedades contagiosas en el puerto de salida de las embarcaciones; su posesión era obligatoria para evitar pasar la cuarentena. En la patente se consignaba el nombre del barco, el puerto de destino y el tipo de mercancías que transportaba. Normalmente las cargas se describían especificando tan sólo la mercancía principal.

Los puertos de Valencia y Tarragona eran, con diferencia, los principales destinos del comercio de cabotaje originado en Malgrat. Sobre un total de 5.112 expediciones realizadas entre 1868 y 1886, 1.998 se dirigieron a Valencia (un 39\%), y 1.153 a Tarragona (un 23\%). La mercancía consignada para ambos puertos era, en el 90\% de los casos, «aros» o, simplemente, «madera» (Mola Vila, 1996). Y casi otro tanto ocurría con los embarques realizados hacia Alicante (702 salidas, de las cuales el 94\% expediciones de madera), Barcelona (420 salidas, un $63 \%$ con madera) y Castellón (409 salidas, un $88 \%$ con madera). En suma, una parte de la madera crecida en el macizo del Montnegre (y del Montseny), transformada generalmente en aros y duelas, tenía como punto de destino los puertos del Mediterráneo, desde Barcelona a Alicante.

No hemos localizado ninguna investigación monográfica sobre el carboneo en las sierras del Montnegre-Corredor, análoga a las disponibles acerca del macizo del Montseny (ver Zamora, 1996; Panareda, 2007; Panareda y Masnou, 2010). Sin embargo, los vestigios de carboneras son muy abundantes tanto en el Montnegre como en el Corredor, y nada hace suponer que esta actividad tuviera un carácter diferente a la que se registraba en el Montseny. Las salidas de carbón vegetal por el puerto de Malgrat, que pueden documentarse a través de la Estadística del Comercio de Cabotaje, eran veinte veces superiores a las salidas de leña. Atendiendo a la mejor relación peso/valor del carbón respecto a la leña, es razonable suponer que la mayor parte de la leña gruesa fuese transformada in situ en carbón vegetal.

Los combustibles constituían, al igual que la madera, un producto de exportación de primer orden, siendo los principales mercados Barcelona y Tarragona. Laureano Figuerola indica en su Estadística de Barcelona en 1849, que uno de los puertos desde donde se abastecía la ciudad de Barcelona de leña y carbón vegetal era Arenys de Mar (Figuerola, 1849, 230). En la relación de puertos abastecedores de Barcelona brindada por Figuerola no figura Malgrat, pero debería haber figurado. Los embarques de carbón vegetal desde los puertos de Arenys de Mar y Malgrat a mediados del XIX (más de 25.000 quintales anuales) suponían una cifra de mucha consideración. Equivalían, por poner una comparación, a la cuarta parte del carbón vegetal que entraba en Barcelona por vía marítima.

Amén de ser productos exportables, los combustibles tenían una importante demanda local. Las fraguas de los astilleros, los hornos de los alfareros y fabricantes de ladrillos, y las destilerías, por citar tres industrias con fuerte presencia en el área, eran importantes consumi- 
dores de leña y carbón vegetal. A partir de mediados del siglo XIX, y en algunas industrias, el carbón mineral comenzó a desplazar al carbón vegetal. De cualquier modo, la leña y el carbón vegetal siguieron siendo durante toda la segunda mitad del ochocientos los combustibles domésticos por excelencia, y tuvieron asegurada una cuota de mercado importante como combustibles industriales.

Sabemos todavía poco acerca de la demanda local de maderas y de combustibles, y de sus efectos sobre la economía forestal del área del Montnegre-Corredor. Será preciso un mayor esfuerzo de investigación para documentar la actividad de leñadores, carboneros y transportistas. También para identificar aquellas industrias que tenían una mayor demanda de madera y combustibles vegetales, y ponderar su actividad. Los tres apartados siguientes exponen algunas noticias sobre tres tipos de actividades manufactureras con un fuerte arraigo en la zona, que eran demandantes netos de productos forestales: la construcción naval, la manufactura del vidrio y la manufactura corchotaponera.

\section{LA CONSTRUCCIÓN NAVAL}

El destino principal para las maderas del Montnegre-Corredor era la construcción de navíos. Los astilleros de la costa de Llevant vivieron una auténtica edad de oro en los años centrales del ochocientos. Tras un período de profunda crisis a finales del siglo XVIII y comienzos del XIX, la construcción de barcos de vela experimentó en Cataluña una espectacular expansión, que se iba a prolongar hasta la década de 1860. Entre los factores responsables de esta recuperación figuran el crecimiento del comercio de cabotaje, la expansión del comercio colonial y la aplicación de medidas arancelarias fuertemente proteccionistas (Pascual, 1991, 301). El crecimiento económico del ochocientos, unido a las barreras arancelarias, tiraron con vigor de la construcción naval doméstica.

La bibliografía especializada destaca el carácter tradicional de la arquitectura naval catalana (cf. Llovet, 1970; Pascual, 1991). Los astilleros estaban dirigidos por carpinteros de ribera, que se encargaban también del diseño de las naves. La construcción de los cascos se efectuaba directamente en las playas, sin contar con ningún tipo de instalación permanente. Una vez finalizado y calafateado el casco, la embarcación solía remolcarse hasta el puerto de Barcelona. Allí se procedía a la instalación de la arboladura, el velamen y los accesorios del navío.

La localización de los astilleros presente un patrón espacial característico: lo puertos de la Marina de Levante, desde Barcelona a Palamós. Sin embargo, la industria naval más importante se concentraba en unas pocas poblaciones: el 55\% de los veleros de más de 80 toneladas de arqueo se construyeron, durante el siglo XIX, en el sector de costa que va de Mataró a Blanes (Ricart, 1924). Arenys de Mar y Blanes fueron, con marcada ventaja, los principales centros de construcción naval.

Los motivos de esta pauta locacional son obvios. La materia prima esencial de la industria era la madera. Las cuadernas de las naves se hacían con madera de roble. Una vez completado el costillaje del barco se añadía la tablazón hecha de madera de pino. La necesidad de maderos curvados, o de «compás», obligaba a recurrir, en ocasiones, a la madera de encina. Para las piezas del interior del barco se utilizaba también madera de olmo, chopo, fresno y nogal. Los tipos de maderas citadas se obtenían de los bosques del país. La única excepción 
de relieve la constituía la madera para arboladura de los veleros, generalmente de abeto o pino melis, que debía ser objeto de importación.

Dada la inmediatez a los puertos de Arenys de Mar y Blanes, los montes del macizo de Montseny y del Montnegre-Corredor debieron constituir una de las principales fuentes de suministro para los astilleros. Sin embargo, hasta donde sabemos, nadie ha estudiado con detalle la procedencia exacta de las materias primas empleadas en la construcción naval. Tampoco disponemos de una estimación precisa del consumo de madera para tales fines.

Una de las mayores dificultades para realizar una aproximación cuantitativa al gasto real de madera en los astilleros deriva de la extrema diversidad de las embarcaciones construidas. En las playas de la costa de Llevant se varaban desde pequeñas barcas de pesca hasta grandes fragatas de tres palos, cuyo arqueo podía superar las 500 toneladas. Por citar un ejemplo, entre 1824 y 1845 los carpinteros de ribera de Arenys de Mar construyeron 80 veleros de gran porte, dedicados al tráfico de altura (fragatas, bergantines y polacras). A esta importante producción hay que agregar 134 barcos destinados al tráfico costero (laúdes, balandras y queches, de entre 4 y 15 toneladas de arqueo), y 132 barcos de pesca de entre dos y cuatro toneladas de arqueo (cf. Llovet, 1970). La relación excluye un número indeterminado (pero seguramente importante) de barcas de pesca, de las que no consta registro alguno. Dado que los requerimientos de madera variaban según el arqueo de los buques, según la línea del casco, y según la función de las embarcaciones, resulta prácticamente imposible realizar estimaciones realistas de la demanda agregada de madera.

La detallada investigación realizada por Joaquim Llovet (1970) sobre la construcción de veleros con un arqueo superior a las 50 toneladas permite, no obstante, seguir con bastante precisión el movimiento de auge y declive de los astilleros de la costa de Llevant a lo largo del siglo XIX. En total, en el citado sector costero, se vararon 426 barcos con un arqueo superior a las 50 toneladas cada uno. El mayor número de veleros se construyó en Arenys de Mar (194 barcos) y Blanes (186). La actividad de los astilleros de Calella, Canet de Mar, Malgrat y Mataró fue mucho más reducida e intermitente, al menos por lo que respecta a los barcos de gran porte. La etapa que media entre 1816 y 1830 se caracterizó por una reducida actividad, construyéndose muy pocos barcos y de reducido porte. El colapso del comercio marítimo catalán provocado por las guerras con Gran Bretaña y Francia, y la pérdida del imperio colonial español, provocaron una fuerte crisis de la industria naval, que se prolongó hasta casi finales del primer tercio del ochocientos. A partir de 1830 se registró un impresionante impulso de la construcción naval que se mantendría durante tres décadas seguidas. El número de veleros varados alcanzó su cenit en el quinquenio 1836-1840 (más de 70 barcos construidos). La estabilización del número de pedidos en las décadas de 1850 y 1860 quedó ampliamente compensada por un patente crecimiento del arqueo de los buques, que casi llegó a triplicarse respecto a las décadas anteriores (ver tabla 5). Durante los años citados, la tendencia al alza de la industria naval tan sólo se vio interrumpida por coyunturales regresiones del comercio marítimo, como la que se produjo en el período 1842-1844.

Esta positiva evolución se vio bruscamente truncada a partir de 1860. La guerra civil norteamericana redujo drásticamente las exportaciones de algodón desde los Estados Unidos de América. La desaparición del algodón en rama de los mercados provocó la desarticulación temporal del comercio catalán con ultramar, originando una crisis inmediata en la industria de construcción naval. La reforma arancelaria liberal de 1869, que puso fin a la mayor parte 
de las medidas proteccionistas que afectaban a la industria naval doméstica, constituyó otro duro golpe para los astilleros de la Marina de Levante. Muy poco después, la marina de vapor empezaría a ganar la batalla a la marina de vela, provocando el colapso definitivo de los tradicionales astilleros catalanes.

Tabla 5

CONSTRUCCIÓN DE VELEROS DE MÁS DE 50 TONELADAS DE ARQUEO EN LOS PUERTOS DE LA MARINA DE LEVANTE COMPRENDIDOS ENTRE MATARÓ Y BLANES (1816-1875)

(Arqueo en toneladas)

\begin{tabular}{|c|c|r|r|r|}
\hline Años & Arenys de Mar & Blanes & Otros puertos* & \multicolumn{1}{c|}{ Total } \\
\hline $1816-20$ & 603 & 0 & 300 & 900 \\
\hline $1821-25$ & 1.053 & 238 & 0 & 1.291 \\
\hline $1826-30$ & 688 & 210 & 130 & 1.28 \\
\hline $1831-35$ & 2.954 & 1.912 & 260 & 5.126 \\
\hline $1836-40$ & 4.840 & 2.580 & 278 & 7.698 \\
\hline $1841-45$ & 1.690 & 1.266 & 293 & 3.249 \\
\hline $1846-50$ & 4.461 & 4.172 & 1.711 & 10.344 \\
\hline $1851-55$ & 4.195 & 5.572 & 4.137 & 13.904 \\
\hline $1856-60$ & 3.161 & 7.145 & 4.359 & 14.665 \\
\hline $1861-65$ & 2.201 & 3.499 & 0 & 5.700 \\
\hline $1866-70$ & 1.809 & 4.371 & 0 & 6.180 \\
\hline $1871-75$ & 319 & 1.626 & 0 & 1.945 \\
\hline & & & & \\
\hline Total & 27.974 & 32.591 & 11.468 & 72.033 \\
\hline
\end{tabular}

(*) Calella, Canet de Mar, Malgrat y Mataró.

Fuente: Elaboración propia a partir de Llovet, 1970.

\section{LA MANUFACTURA DEL VIDRIO}

La manufactura del vidrio, una actividad industrial con una fuerte demanda de combustible, ha tenido una larga tradición en la zona del Maresme. La presencia de maestros vidrieros en Mataró se remonta a comienzos del siglo XVI. Albert García Espuche y Manuel Guàrdia, estudiosos de la historia urbana de Mataró, han documentado la actividad de 28 vidrieros en la ciudad entre 1571 y 1605: una cifra muy importante para una manufactura tan especializada como el vidrio. Según la interpretación de los autores citados, la producción y comercialización del vidrio fue, junto con la especialización vinícola, una de las bases fundamentales para la expansión urbana de la ciudad en los siglos XVI y XVII (García Espuche y Guàrdia Bassols, 1989: 40-41).

El desarrollo de la industria vidriera en Mataró y su entorno ha sido presentado como un ejemplo característico de la descentralización territorial que se produjo desde Barcelona a las poblaciones de su área de influencia desde 1550 a 1640 (García Espuche, 1998). La producción vidriera realizada en el Maresme, por los «vidrieros de horno», era vendida en la capital por los «vidrieros de tienda». En ocasiones, según la interpretación avanzada por Gar- 
cía Espuche (1998: 214), los vidrieros-comerciantes barceloneses manipulaban el vidrio en sus pequeños talleres para añadir valor al producto con trabajos de ornamentación. Durante el siglo XVII, y también en el XVIII, los vidrios fabricados en Mataró abastecían en primer lugar al potente mercado barcelonés, pero la red comercial edificada en el Maresme llegó a extenderse por Castilla, Francia, el norte de África y América.

Aunque distintas fuentes confirman la existencia de hornos de vidrio en la misma ciudad de Mataró (García Espuche y Guàrdia Bassols, 1989; Martí Coll, 1996), lo cierto es que la industria tradicional del vidrio tenía una vocación eminentemente rural. La producción básica de vidrio requiere el empleo de inputs de mucho peso: arenas y productos de cantera y grandes cantidades de leña y carbón vegetal que se empleaban como combustible. Un horno de vidrio podía llegar a consumir 8.000 quintales de leña en un período de seis meses. Dado el elevado coste del transporte terrestre, lo lógico es que la primera fundición se realizara en el lugar más próximo a la fuente de los recursos citados. García Espuche (1998) ha indicado que los vidrieros de Mataró acostumbraban a poseer o alquilar hornos en lugares como Sant Genís de Vilassar, Vallgorguina y Dosrius. En realidad el éxito del vidrio del Maresme parece inseparable de la buena dotación de recursos que ofrecen las sierras del Montnegre y el Corredor. En efecto, la abundancia de rocas silíceas y la facilidad para aprovisionarse de combustible vegetal eran condiciones esenciales para la localización de los hornos.

La dispersión de los hornos de vidrio en el área del Montnegre-Corredor puede confirmarse a partir de algunos documentos cartográficos: la planimetría del término municipal de Montnegre a escala 1:25.000, levantada por el topógrafo Fernando García Verdugo en 1924, registra la existencia de un horno de vidrio situado junto a la capilla de Fuirosos; en la hoja n 393 del Mapa Militar de España a escala 1:50.000 se consignan los restos de un horno de vidrio emplazado a 500 metros de altitud en la sierra del Corredor.

El patrón geográfico de la industria del vidrio en la zona de estudio debió ser, por tanto, muy semejante al característico de la siderurgia tradicional. La dispersión en las áreas rurales de los hornos de primera fundición, para minimizar los costes de transporte, y la concentración en las ciudades, y sobre todo en las ciudades portuarias, de los talleres de ornamentación y los almacenes comerciales. Mataró, y Arenys de Mar, cumplieron esta última función. Este mismo patrón geográfico se mantenía todavía en el siglo XIX.

La persistencia de la industria vidriera en la zona durante la primera mitad del siglo XIX está ampliamente documentada. La Guía del Ministerio de la Gobernación correspondiente a 1836 indica que en Arenys de Mar «se trabajan vidrios planos muy cristalinos para vidrieras de todas dimensiones hasta de vara y media de largo sobre el ancho correspondiente» (Ministerio de la Gobernación, 1836, 150). El Nomenclátor de 1860 confirma la existencia de dos fábricas dedicadas a la producción de vidrio en la misma población (Junta General de Estadística, 1863-1871). Por su parte, Pascual Madoz da cuenta en su Diccionario (1845) de la actividad de una fábrica de vidrio en Mataró dedicada a la producción de botellas, vasos y vidrios planos: en total empleaba 30 operarios. La misma fuente anota la existencia de una segunda fábrica, con 20 trabajadores, en el lugar de Alfar, perteneciente al término municipal de Dosrius.

Nada sabemos realmente respecto a la capacidad de producción de estos establecimientos, aunque atendiendo al número de empleados que consigna Pascual Madoz para las fábricas de Mataró y Dosrius, la escala de producción debía ser relativamente modesta. En cualquier 
caso no era despreciable. En la aduana de Mataró, que controlaba el comercio de cabotaje, se registró una salida media anual de 1.707 arrobas de vidrio común (18 toneladas aproximadamente) en los años 1844 y 1845. La Estadística General del Comercio de Cabotaje, compilada con regularidad a partir de 1857, no registra salidas de vidrio desde Mataró, pero si desde Arenys de Mar: 80 y 97 quintales embarcados respectivamente en 1858 y 1859. La cifra es muy corta; poco más de tres toneladas de media anual. Es posible que por entonces la industria vidriera se viese restringida al mercado local debido a la competencia de nuevos productores.

En la década de 1840 se había producido la entrada en funcionamiento de cinco fábricas de vidrio localizadas respectivamente en Gijón (1843), Avilés (1845), Campóo (1845), Bilbao y A Coruña (Sierra Álvarez, 1992, 67). Se trata, en todos los casos, de fábricas que contaban con potentes hornos alimentados con carbón mineral. Dada la estrechez del mercado del vidrio en España, señalada por Sierra Álvarez (1992), la aparición casi simultánea de tantos nuevos competidores debió suponer una dura prueba para la tradición vidriera del Maresme. No hemos encontrado ninguna mención, en la historiografía industrial catalana, al desarrollo de la industria del vidrio en Arenys y Mataró para la segunda mitad del siglo XIX.

\section{LA MANUFACTURA CORCHOTAPONERA}

La corteza del alcornoque (Quercus suber) era objeto de aprovechamiento desde tiempo inmemorial. Por sus condiciones de flotabilidad se empleaba para la fabricación de artes de pesca en toda la zona litoral. También se utilizaba para la fabricación de colmenas de corcho, y como impermeabilizante para algunos tipos de calzado. Se trataba, no obstante, de aprovechamientos tradicionales con una demanda bastante limitada. La era comercial del corcho se inició en Francia, a finales del siglo XVII, cuando se difundió la elaboración del «champagne». El corcho de alcornoque, flexible, dúctil e impermeable, constituye el material ideal para la fabricación de tapones destinados a obturar las botellas de vino espumoso.

La demanda de tapones especializó las regiones suberícolas del sur de Francia, señaladamente la región provenzal, y a lo largo del siglo XVIII la manufactura corchotaponera se fue expendiendo por Cataluña (Barbaza, 1986). En el área catalana la progresión de la industria del corcho se realizó de norte a sur: desde las sierras de l'Albera y las Salinas hasta las zonas suberícolas del macizo del Montnegre. A finales del setecientos se registran las primeras noticias de maestros taponeros trabajando en Arenys de Mar (Palomer, 1996; Alvarado, 2005).

A lo largo del siglo XIX la industria corchotaponera acabó cristalizando en dos grandes subregiones que vienen a coincidir con las zonas de dominio potencial del Quercus suber. En las proximidades de la frontera pirenaica, los fabricantes de tapones del Alt Empordà aprovechaban los bosques de alcornoques del macizo de l'Albera y las Salinas. Los principales centros corchotaponeros eran Agullana, Darnius, Maçanet de Cabrenys y La Jonquera. Mas al sur, en la zona suberícolas que se extiende por las sierras de Gavarres, Guilleries y la vertiente suroriental del Montseny, se organizó un potente distrito manufacturero cuyos principales centros eran Palafrugell, Sant Feliu Guíxols y Cassà de la Selva. Los bosques de alcornoques del Montnegre-Corredor suministraron la materia prima necesaria para prolongar meridionalmente este distrito gerundense hasta el Maresme. Arenys de Mar se constituyó como el principal núcleo manufacturero del área meridional. 
En las zonas citadas la disponibilidad de materia prima fue la condición necesaria para la implantación de la industria del corcho. Pero el desarrollo manufacturero dependió también de la buena localización respecto a los principales centros comerciales. El corcho catalán se comercializaba, inicialmente, a través de la feria de Bèucaire, en las proximidades de Nimes. El fácil acceso por vía marítima a la región corchera catalana multiplicó sus posibilidades de éxito. Un último factor puede haber sido determinante: la presencia de artesanos hábiles y de mano de obra especializada en la pela y manipulación del corcho. En sus orígenes, y durante la mayor parte del siglo XIX, la industria corchotaponera fue una manufactura típica, intensiva en trabajo especializado y de difícil mecanización (para detalles sobre la manipulación del corcho ver Palomer, 1996).

La actividad corchotaponera en la zona del Montnegre-Corredor significaba una fracción menor del conjunto de la industria corchera catalana. En 1842 se registraba la existencia de «fábricas» de corcho en Olzinelles, Tordera y Arenys de Mar. Más que fábricas en sentido moderno, se trataba de empresas familiares de tipo doméstico, o de pequeños talleres que daban trabajo, a lo sumo, a una docena de operarios. La única concentración importante era Arenys de Mar, donde se había organizado una auténtica red de empresas del sector, que totalizaba 27 establecimientos. Jordi Palomer (1996) indica la existencia de tres fabricantes de tapones en 1840, debiendo corresponder el resto, hasta 27, a empresas de carácter puramente familiar.

Mayor precisión ofrecen las cifras relativas al año 1884, ya que para esa fecha contamos con un censo de empleados del sector. La industria del corcho daba trabajo, por entonces, a cerca de 400 operarios en la zona del Montnegre-Corredor, que representaban casi un 5\% de la manufactura catalana del corcho. Arenys de Mar continuaba siendo el centro principal, con una veintena de empresas y 306 operarios (300 hombres y 6 mujeres). La producción de los fabricantes de Arenys de Mar se cifraba en 62 millones de tapones anuales de corcho, con un peso total de 186.000 kilogramos. Aunque las cifras de producción y empleo estaban lejos de los principales centros corchotaponeros (Palafrugell, Sant Feliu de Guíxols y Cassà de la Selva contaban, ese mismo año, respectivamente, con más de 1.000 trabajadores cada uno), se trataba de una manufactura importante a nivel local.

La mecanización de la elaboración de tapones de corcho se inició, en Cataluña, en la década de 1880. En 1886 la casa José Batet de Sant Feliu de Guíxols disponía ya de 33 máquinas taponeras Nowe-Derwuel (Sala, 1997; Sala y Nadal, 2010). Mientras que la producción manual de un maestro taponero se estimaba en 1.000 ó 1.500 tapones por día, la adopción de las primeras máquinas permitió multiplicar por cinco el producto diario de los operarios fabriles. A partir de finales de siglo las principales factorías de Sant Feliu de Guíxols, Cassà y Palafrugell incorporaron maquinaria cada vez más eficiente, que acabó por transformar la manufactura corchera en un sector fabril moderno. Los talleres de Arenys de Mar quedaron, aparentemente, al margen de este proceso modernizador.

Los 25 fabricantes de tapones de corcho registrados en Arenys de Mar en el año 1880 se habían reducido a 18 en 1900, y a cinco en 1930 (Palomer, 1996). Tras la guerra civil la manufactura del corcho desapareció definitivamente de la zona. La mecanización de la industria, con sus mayores exigencias de capital, provocó una característica concentración empresarial y geográfica de la producción. Algunos de los mayores empresarios de Arenys de Mar relocalizaron sus fábricas en Sant Feliu, dónde resultaba más fácil proveerse de 
corcho, acceder a las redes comerciales y encontrar mano de obra especializada. Desde mediados del siglo XIX la producción catalana de corcho virgen no bastaba para atender la demanda industrial. La necesidad de importar cantidades crecientes de cortezas desde Extremadura y Andalucía había dado ventaja a los principales centros manufactureros del Baix Empordà, donde se concentraron los depósitos y almacenes de corcho, y también las empresas comerciales exportadoras. Los pequeños talleres manufactureros, enfrentados a la competencia de la fabricación mecánica, estaban condenados a desaparecer.

\section{CONCLUSIONES}

Pese al retroceso de las masas forestales, muy patente en casi toda Cataluña desde el siglo XVIII, los bosques seguían ocupando un importante lugar en el paisaje de las sierras del Corredor y el Montnegre a mediados del ochocientos. En la década de 1850 el área dedicada a uso forestal suponía aproximadamente un 35\% de la superficie geográfica. La mayor parte de la superficie forestal estaba ocupada por montes destinados a la producción de leña y carbón vegetal. Existía también una importante dotación de bosques maderables (principalmente pinares y robledales), y de alcornocales dedicados a la producción de corcho. Los árboles de ribera y los sotos de castaños completaban la oferta forestal.

Los bosques eran objeto de un aprovechamiento minucioso. Además de la explotación de maderas y combustibles, se recogían piñas, cortezas de pino y encina, y cenizas, estas últimas empleadas para la fabricación de jabón. La cercanía de los puertos al área forestal facilitaba las posibilidades de comercialización para estos productos de bajo valor unitario. Los productos forestales abastecían el mercado local y constituían una de las principales materias de exportación. Desde los puertos de Arenys de Mar, Malgrat de Mar y Mataró se exportaban anualmente más de 80.000 quintales de madera (principalmente roble, pino y encina) y 25.000 quintales de carbón vegetal. En su conjunto, estas exportaciones suponían un $40 \%$ de las mercancías comercializadas.

La presión sobre el bosque puede haber alcanzado su cenit justamente a mediados del siglo XIX. La demanda de madera para la construcción naval, que había crecido impetuosamente durante la primera mitad del ochocientos, comenzó a declinar de modo muy marcado a partir de 1860. El declive de la construcción naval coincidió con el ocaso de los hornos dedicados a la fabricación de vidrio, una actividad tradicional en los montes del MontnegreCorredor, que era muy intensiva en el consumo de combustible. Al propio tiempo, la presión roturadora de la viticultura se vió temporalmente frenada por la difusión de la plaga del oidium. Es muy posible que la recuperación del bosque se iniciase con una expansión de los alcornocales, dada la fuerte demanda de corteza de corcho en la época.

\section{BIBLIOGRAFÍA}

ALVARADO COSTA, J. (2005): Industrials i tapers (del segle XVIII al XX). Cassà de la Selva. Ajuntament de Cassà de la Selva.

BARBAZA, Y. (1986): El paisatge humà de la Costa Brava. Barcelona. Edicions 62.

CASALS, V. et. al. (2005): La transformación histórica del paisaje forestal en Cataluña. Madrid. Ministerio de Medio Ambiente. 
FIGUEROLA, L. (1849): Estadística de Barcelona en 1849. Barcelona. Imprenta y Librería Politécnica de Tomás Gorchs.

GARCÍA ESPUCHE, A. (1998): Un siglo decisivo. Barcelona y Cataluña, 1550-1640. Madrid, Alianza Editorial.

GÓMEZ ORTIZ, A., MATEU GIRAL, J. y FERNÁNDEZ VIADER, P. (1985): El Maresme: Geografía y recursos didàctics. Barcelona. Edicions de la Universitat de Barcelona.

LLOBET, S. (1955): «De geografía agraria de la comarca del Maresme (Barcelona)». Estudios Geográficos, n ${ }^{\circ}$ 58, 23-72 y 215-297.

LLOBET, S. (1968): «El Maresme», en Geografia de Catalunya (Solé Sabaris, Ll., dir.). Barcelona, Aedos, vol. III, 405-448.

LLOVET, J. (1970): Constructors navals de l'exprovíncia marítima de Mataró, 1816-1875. Mataró. Caixa d'Estalvis Laietana.

LLOVET, J. (1980): La matrícula de mar i la província de Marina de Mataró al segle XVIII. Mataró. Caixa d'Estalvis Laietana.

MARTÍ COLL, A. (1996): «La indústria del vidre a Mataró al primer terç del segle XVII i el naixement de Pascual d'Aragó», en XII Sessió d'Estudis Mataronins. Mataró, Arxiu de Santa Maria, 199-204.

MINISTERIO DE LA GOBERNACIÓN (1836): Guía del Ministerio de la Gobernación del Reino, para el presente año de 1836. Madrid. Imprenta Real.

MONTANER, C., NADAL, F. y URTEAGA, L., eds. (2011): Cartografia i agrimensura a Catalunya i Balears als segle XIX. Barcelona. Institut Cartogràfic de Catalunya.

NADAL, F. y URTEAGA, L. (2001): «Un plànol d'usos del sòl del municipi de Tordera a mitjan segle XIX», en III Trobada d'Estudiosos del Montnegre i el Corredor, Barcelona, Diputació de Barcelona, 137-142.

NADAL, F. y URTEAGA, L. (2008): «L'impacte geogràfic de la plaga de l'oïdi sobre el vinyar català: el cas de la comarca del Maresme (1852-1862)». Cuadernos de Geografía, $\mathrm{n}^{\circ} 83,39-60$.

NADAL, F., URTEAGA, L. y MURO, J. I. (2005): «La documentación cartográfica de la Contribución de inmuebles, cultivo y ganadería: el caso de la provincia de Barcelona (1845-1895)». Boletín de la Asociación de Geógrafos Españoles, no 40, 83-109.

NADAL, F., URTEAGA, L. y MURO, J. I. (2006): El territori dels geòmetres. Cartografia parcel.lària dels municipis de la provincia de Barcelona (1845-1895). Barcelona. Institut d'Edicions de la Diputació de Barcelona.

OTERO, I., BOADA, M. y REDOREDA, G. (2007): La vall d'Olzinelles. Els dominis de l'alzinar i la sureda. Sant Celoni. Ajuntament de Sant Celoni.

PALOMER PONS, J. (1996): La indústria del suro a Arenys de Mar. La fabricació de taps. Segles XIX-XX. Argentona. L'Aixernador Edicions.

PANAREDA, J. M. (2007): «El carboneig, un ofici tradicional en el Montseny que ha deixat una forta emprenta en el paisatge. Tagamanent, $\mathrm{n}^{\circ}$ 58, 30-35.

PANAREDA, J. M. y MASNOU, J. (2010): El carboneig. Quan el record encara és viu. Barcelona. Publicacions de l'Abadia de Montserrat.

PARCERISAS, Ll. y TELLO, E (2011): «Els canvis en els usos del sòl al Maresme (18502007)», en Cartografia i agrimensura a Catalunya i Balears als segle XIX (Montaner, C., Nadal, F. y Urteaga, L., eds.). Barcelona, Institut Cartogràfic de Catalunya, 249-261. 
PASCUAL, P. (1991): «Els transports», en Història econòmica de la Catalunya contemporània (Nadal, J., dir.). Barcelona, Enciclopèdia Catalana, vol. III, 233-335.

PORTALS, J. (1998): El Montnegre. Una història de mil anys. Arenys de Mar. Llibreria El Setciències.

RIGALT, J. (1924): «El siglo de oro de la marina velera de construcción catalana, 17901870». Memorias de la Real Academia de Ciencias y Letras de Barcelona, 3 a época, vol. XVIII, n ${ }^{\circ} 7,177-201$.

SALA, P. (1997): Taller, industria y aranceles en el distrito corchotaponero catalán. Algunas hipótesis y propuestas interpretativas, en La riqueza de las regiones. Análisis espacial de la industrialización (VI Congreso de la Asociación de Historia Económica). Mecanografiado, 388-404.

SALA, P. y NADAL, J. (2010): La contribució catalana al desenvolupament de la indústria surera portuguesa. Barcelona. Generalitat de Catalunya.

SERRA CERVANTES, I. y PINTÓ FUSALBA, J. (2005): «La transformació del paisatge del delta de la Tordera en els darrer cent cinquanta anys. Una anàlisi per mitjà dels canvis en els usos i les cobertes del sòl». Documents d'Anàlisi Geogràfica, nº 45, 81-102.

SIERRA ÁlVAREZ, J. (1992): «El complejo vidriero de Campóo (Cantabria), 1844-1928. Una aportación a la historia de la industria española del vidrio». Revista de Historia Industrial, $\mathrm{n}^{\mathrm{o}} 2,63-86$.

VALLEJO, R. (2001): «Los amillaramientos como fuente estadística: una visión crítica desde la contribución territorial». Historia Agraria. Revista de agricultura e historia rural, $\mathrm{n}^{\circ} 20,89-116$.

VALLS, F. (1996): La dinàmica del canvi agrari a la Catalunya interior. L'Anoia, 17201860. Barcelona. Publicacions de l'Abadia de Montserrat.

ZAMORA ESCALA, J. E. (1996): El carboneig al Montseny. Barcelona. Associació d'Enginyers Industrials de Catalunya. 
Anexo I

COMPARACIÓN ENTRE LA SUPERFICIE GEOGRÁFICA Y LA SUPERFICIE AMILLARADA EN LOS MUNICIPIOS DEL ÁREA DE ESTUDIO (1852)

\begin{tabular}{|l|c|c|c|}
\hline Municipios & $\begin{array}{c}\text { Superficie geográfica } \\
\left(\mathbf{k m}^{2}\right)\end{array}$ & $\begin{array}{c}\text { Superficie } \\
\text { amillarada } \\
\left(\mathbf{k m}^{2}\right)\end{array}$ & $\begin{array}{c}\text { \% Superficie } \\
\text { amillarada sobre la } \\
\text { superficie geográfica }\end{array}$ \\
\hline Arenys de Mar & 6,5 & 4,8 & 73,9 \\
\hline Arenys de Munt & 20,8 & 14,9 & 71,6 \\
\hline Caldes d'Estrac & 0,7 & 0,5 & 71,4 \\
\hline Calella & 7,9 & 4,1 & 51,9 \\
\hline Canet de Mar & 6,2 & 6,2 & 100,0 \\
\hline Dosrius & 40,8 & 37,2 & 91,2 \\
\hline Fogars de Tordera & 33,2 & 29,7 & 89,5 \\
\hline Hortsavinyà & 29,6 & 18,5 & 62,5 \\
\hline Llinars del Vallès & 27,5 & 25,1 & 91,9 \\
\hline Malgrat de Mar & 9,1 & 4,5 & 49,5 \\
\hline Mataró & 22,6 & 19,9 & 88,1 \\
\hline Montnegre & 31,4 & 28,8 & 91,7 \\
\hline Olzinellas & 23,5 & 22,1 & 94,1 \\
\hline Palafolls & 16,3 & 17,5 & 107,3 \\
\hline Pineda de Mar & 10,4 & 7,8 & 75,0 \\
\hline Sant Andreu de Llavaneres & 11,9 & 9,9 & 83,2 \\
\hline Sant Cebrià de Vallalta & 15,8 & 13,5 & 85,5 \\
\hline Sant Iscle de Vallalta & 17,7 & 16,8 & 94,9 \\
\hline Sant Pol de Mar & 7,5 & 6,1 & 81,4 \\
\hline Sant Vicenç de Montalt & 8,0 & 7,8 & 97,5 \\
\hline Santa Susanna & 12,5 & 10,7 & 85,6 \\
\hline Tordera & 54,2 & 50,5 & 93,2 \\
\hline Vallgorguina & 22,0 & 20,1 & 91,4 \\
\hline Vilalba Sasserra & 5,9 & 4,4 & 86,3 \\
\hline Total & 44,0 & 381,5 & \\
\hline & & & \\
\hline & & & \\
\hline
\end{tabular}

Fuente: Elaboración propia a partir de las fuentes indicadas en la Tabla 1. 
